\title{
Physiologic approach to diuresis in de- resuscitation phase in intensive care
}

\author{
Amos Lal ${ }^{*}$ (D) and Juan Pablo Domecq Garces
}

To the Editor,

We read with great interest the paper by Bissell et al. regarding impact of protocolized diuresis for de-resuscitation in the intensive care unit [1]. This document is timely in the era where intensivists are taking a more detailed focus on acute fluid resuscitation and de-resuscitation periods.

After reading the paper carefully, we would like to stress the fact that even when the protocol is showing interesting results, the protocol is still not based on physiologic data, something that is much needed at the time to care for critically ill patient. Indications for combination therapy were recommended only after reaching the maximum dose of furosemide or developing side effects (hypernatremia), when in fact, obese patients and patient on chronic diuretic therapy could benefit from adding thiazides as initial approach [2] due to high risk for distal tubular hypertrophy. Also, the electrolyte protocol does not comment on the importance of focusing on sodium and chloride both electrolytes independently and inversely associated with mortality in patients with volume overload. This is taking even more momentum now that hypertonic saline has been proposed as an effective intervention to increase diuretic efficiency [3].
Also we would like to point out a detail in the "Abstract" section; authors present post-shock fluid balance as median and interquartile range, whereas in the "Results" section (Table 3) the same outcomes were presented as average and standard deviation. This discrepancy affects the readability of results since there is a considerable difference between the two statistical measures. Also, upon cautious appraisal, it is difficult to interpret the results in the same table (Table 3 Clinical outcomes) when authors present post-shock fluid balance. For example, the 72-h fluid balance in the intervention cohort the average fluid balance is $-2257 \mathrm{~mL}$ with standard deviation being -5676-920; does this mean that the standard deviation ranges from -5676 to $-920 \mathrm{~mL}$ or -5676 to $+920 \mathrm{~mL}$ ? Although these may be visually minor appearing typographical inaccuracies, they greatly impact the understanding of the results from this paper.

We agree that protocolized diuresis is promising, and we would like to emphasize the need to maintain a physiologic approach for these protocols. As well, we would suggest incorporating into the original manuscript as an erratum will give a much clearer insight to the readers of the journal and greater scientific community.

\section{Authors' response}

Brittany D. Bissell; Javier A. Neyra

We thank Lal et al. for their comments [4] concerning our article on the impact of protocolized diuresis for deresuscitation in the intensive care unit [1]. Regarding the

\footnotetext{
*Correspondence: Lal.Amos@mayo.edu; manavamos@gmail.com

This comment refers to the article available at https://doi.org/10.1186/ s13054-020-2795-9.

Division of Pulmonary and Critical Care Medicine, Mayo Clinic, Rochester, MN, USA
}

typographical concerns expressed, all fluid balances reported in the "Results" section and specifically in Table 3 were evaluated via Wilcoxon rank sum and reported as median (interquartile range) (Clinical outcomes). The numbers and ranges are correct as reported. For the cited example in the intervention group, median $72 \mathrm{~h}$

(C) The Author(s). 2020 Open Access This article is licensed under a Creative Commons Attribution 4.0 International License, which permits use, sharing, adaptation, distribution and reproduction in any medium or format, as long as you give appropriate credit to the original author(s) and the source, provide a link to the Creative Commons licence, and indicate if changes were made. The images or other third party material in this article are included in the article's Creative Commons licence, unless indicated otherwise in a credit line to the material. If material is not included in the article's Creative Commons licence and your intended use is not permitted by statutory regulation or exceeds the permitted use, you will need to obtain permission directly from the copyright holder. To view a copy of this licence, visit http://creativecommons.org/licenses/by/4.0/. The Creative Commons Public Domain Dedication waiver (http://creativecommons.org/publicdomain/zero/1.0/) applies to the data made available in this article, unless otherwise stated in a credit line to the data. 
Table 3 Clinical outcomes

\begin{tabular}{|c|c|c|c|}
\hline Parameter & Historical cohort $(n=273)$ & Intervention cohort $(n=91)$ & $p$ value \\
\hline \multicolumn{4}{|l|}{ Clinical outcomes } \\
\hline $72 \mathrm{~h}$ fluid balance $(\mathrm{mL})^{\mathrm{a}}$ & $265(-2283-3025)$ & $-2257(-5676-920)$ & $<0.0001$ \\
\hline $48 \mathrm{~h}$ fluid balance $(\mathrm{mL})^{\mathrm{a}}$ & $309(-1267-2434)$ & $-1799(-3884-1092)$ & $<0.0001$ \\
\hline $24 \mathrm{~h}$ fluid balance $(\mathrm{mL})^{\mathrm{a}}$ & $101(-963-1622)$ & $-692(-1833-697)$ & 0.0002 \\
\hline Ventilator-free days (days) ${ }^{a}$ & $19(10-22)$ & $20(15-23)$ & 0.098 \\
\hline Overall adverse event ${ }^{b, e}$ & $74(27.1)$ & $37(40.6)$ & 0.015 \\
\hline Ventilator days (days) ${ }^{a}$ & $8(5-13)$ & $5(5-12)$ & 0.441 \\
\hline Furosemide to extubation (hours) ${ }^{a}$ & $70(24-147)$ & $58(23-122)$ & 0.282 \\
\hline Re-intubation rate ${ }^{b}$ & $57(20.8)$ & $17(18.6)$ & 0.652 \\
\hline ICU-free days (days) ${ }^{a}$ & $17(7-21)$ & $19(13-22)$ & 0.030 \\
\hline ICU days (days) ${ }^{a}$ & $8.6(6.2-13.5)$ & $8.1(5.9-12.8)$ & 0.513 \\
\hline In-hospital mortality ${ }^{c}$ & $44(16.1)$ & $5(5.5)$ & 0.008 \\
\hline \multicolumn{4}{|l|}{ Safety outcomes } \\
\hline Bolus administration after furosemide ${ }^{c}$ & $4(1.5)$ & $0(0)$ & 0.576 \\
\hline Vasopressor administration after furosemide ${ }^{b}$ & $65(23.8)$ & $19(20.9)$ & 0.566 \\
\hline Tachyarrhythmia $^{\mathrm{b}}$ & $50(18.3)$ & $15(16.4)$ & 0.693 \\
\hline In-hospital mortality ${ }^{c}$ & $44(16.1)$ & $5(5.5)$ & 0.008 \\
\hline RRT receipt in ICU & $17(6.2)$ & $0(0)$ & $<0.0001$ \\
\hline RRT dependence at discharge ${ }^{c}$ & $14(5.1)$ & $0(0)$ & 0.025 \\
\hline Acute kidney injury ${ }^{f}$ & $62(22.7)$ & $22(24.2)$ & 0.775 \\
\hline Hypokalemia $^{c}$ & 0 & $3(3.3)$ & 0.015 \\
\hline Hypernatremia $^{\mathrm{b}}$ & $19(6.9)$ & $19(20.9)$ & 0.001 \\
\hline Metabolic alkalosis ${ }^{c}$ & $3(1.1)$ & $1(1.1)$ & 1.000 \\
\hline
\end{tabular}

Wilcoxon rank sum, median (interquartile range)

${ }^{\mathrm{b}} \mathrm{Chi}$-square test, number (percentage)

'Fisher's exact, number (percentage)

${ }^{\mathrm{d}}$ Student's $t$ test, average (standard deviation)

eOverall adverse event: serum creatinine rise, hypokalemia, hypernatremia, or metabolic alkalosis

${ }^{\mathrm{f}}$ Acute kidney injury: serum creatinine 1.5 times baseline serum creatinine, serum creatinine increase of at least $0.3 \mathrm{mg} / \mathrm{dL}$

fluid balance was $-2257 \mathrm{~mL}$, with 25 th percentile of $5676 \mathrm{~mL}$ and 75th percentile of $920 \mathrm{~mL}$.

We agree with the authors' comments suggesting that physiologic data are important to consider for critically ill patients. We believe, however, there must be a balance between protocol complexity and personalization in therapeutics. This is best exemplified by the largest study modulating fluid balance in a broad critically ill population, the Comparison of Two Fluid-Management Strategies in Acute Lung Injury study [5]. Despite demonstrating significant improvement in mechanical ventilation duration and lung function, this protocol has had limited uptake by the critical care community to everyday practice. We hope to build upon our protocol to develop a more personalized approach to not only de-resuscitation, but volume management at large. To do so, however, two key areas must be researched: (1) loop diuretic pharmacodynamics in the critically ill with and without acute and/or chronic kidney impairment and (2) development of accurate, dynamic predictive models of diuretic responsiveness to simplify and identify target populations for protocolized approaches.

Lal et al. comments on combination diuretic therapy and electrolyte disturbances are pertinent, but it is prudent to understand that our protocol is intended for the broad intensive care unit population, not only those presenting with acute decompensated heart failure. Such patients represent a small portion of the critically ill population, noted by the $6.6-11.1 \%$ incidence of chronic loop diuretic usage and only $2.2-3.3 \%$ of admissions secondary to cardiac procedures in our study [1]. Predominate evidence for utilization of hypertonic saline (HTS) as a diuretic adjunct is restricted to patients presenting with heart failure, and current evidence would advise against such in the general critically ill population given that chloride is directly, rather than inversely, associated with mortality while the correlation with sodium may be biphasic [6, 7]. Until further data are available, HTS 
remains unlikely a feasible addition to broad protocolized approaches at this time. We agree that in patients with chronic exposure to loop diuretics, initial or early combination therapy including thiazides should be considered, particularly given the incidence of hypernatremia in our study.

\section{Acknowledgements}

None

\section{Authors' contributions}

AL: conception of letter + manuscript draft + critical review. JPDG: conception of letter + manuscript draft + critical review. The author(s) read and approved the final manuscript.

\section{Funding}

None

Availability of data and materials

Not applicable

\section{Ethics approval and consent to participate}

Not applicable

\section{Consent for publication}

Not applicable

\section{Competing interests}

None

Received: 10 March 2020 Accepted: 14 April 2020

Published online: 28 May 2020

\section{References}

1. Bissell BD, Laine ME, Thompson Bastin ML, Flannery AH, Kelly A, Riser J, et al. Impact of protocolized diuresis for de-resuscitation in the intensive care unit. Crit Care. 2020;24(1):70.

2. Knauf H, Mutschler E. Low-dose segmental blockade of the nephron rather than high-dose diuretic monotherapy. Eur J Clin Pharmacol. 1993;44(Suppl 1):S63-8.

3. Griffin M, Soufer A, Goljo E, Colna M, Rao VS, Jeon S, et al. Real World Use of Hypertonic Saline in Refractory Acute Decompensated Heart Failure: A U.S. Center's Experience. JACC Heart Fail. 2020:8(3):199-208.

4. Lal A, Domecq Garces JP, Sahu KK, Mishra AK. Physiologic approach to diuresis in de-resuscitation phase in intensive care. Crit Care. 2020 (Ahead of print).

5. National Heart, Lung, and Blood Institute Acute Respiratory Distress Syndrome (ARDS) Clinical Trials Network, Wiedemann HP, Wheeler AP, et al. Comparison of two fluid-management strategies in acute lung injury. $\mathrm{N}$ Engl J Med. 2006;354(24):2564-75.

6. Neyra JA, Canepa-Escaro F, Li X, et al. Association of hyperchloremia with hospital mortality in critically ill septic patients. Crit Care Med. 2015;43(9): 1938-44.

7. Stelfox HT, Ahmed SB, Zygun D, Khandwala F, Laupland K. Characterization of intensive care unit acquired hyponatremia and hypernatremia following cardiac surgery. Can J Anaesth. 2010;57(7):650-8.

\section{Publisher's Note}

Springer Nature remains neutral with regard to jurisdictional claims in published maps and institutional affiliations. 